\title{
Pregnancy-specific glycoprotein 1 (PSG1) activates TGF- $\beta$ and prevents dextran sodium sulfate (DSS)-induced colitis in mice
}

\author{
SM Blois ${ }^{1,5}$, G Sulkowski ${ }^{2,5}$, I Tirado-González ${ }^{1}$, J Warren ${ }^{2}$, N Freitag ${ }^{1}$, BF Klapp $^{1}$, D Rifkin ${ }^{3}$, I Fuss ${ }^{4}$, \\ W Strober ${ }^{4}$ and GS Dveksler ${ }^{2}$
}

Transforming growth factor- $\beta$ s (TGF- $\beta$ s) are secreted from cells as latent complexes and the activity of TGF- $\beta$ s is controlled predominantly through activation of these complexes. Tolerance to the fetal allograft is essential for pregnancy success; TGF- $\beta 1$ and TGF- $\beta 2$ play important roles in regulating these processes. Pregnancy-specific $\beta$-glycoproteins (PSGs) are present in the maternal circulation at a high concentration throughout pregnancy and have been proposed to have anti-inflammatory functions. We found that recombinant and native PSG1 activate TGF- $\beta 1$ and TGF- $\beta 2$ in vitro. Consistent with these findings, administration of PSG1 protected mice from dextran sodium sulfate (DSS)-induced colitis, reduced the secretion of pro-inflammatory cytokines, and increased the number of Tregulatory cells. The PSG1-mediated protection was greatly inhibited by the coadministration of neutralizing anti-TGF- $\beta$ antibody. Our results indicate that proteins secreted by the placenta directly contribute to the generation of active TGF- $\beta$ and identify PSG1 as one of the few known biological activators of TGF- $\beta 2$.

\section{INTRODUCTION}

Transforming growth factor- $\beta$ s (TGF- $\beta$ s) are involved in the regulation of several processes including cell growth, differentiation, and angiogenesis. ${ }^{1}$ In addition, TGF- $\beta$ regulates diverse innate and adaptive immune functions ranging from immune tolerance, tumor rejection, and suppression of autoimmune disorders. ${ }^{2}$ TGF- $\beta$ exists in three isoforms in mammals, TGF- $\beta 1,-\beta 2$, and $-\beta 3$, that are secreted from cells in biologically inactive forms, either as part of a large latent complex or the small latent complex (SLC). The large latent complex is composed of the latent TGF- $\beta$-binding protein, the latency-associated protein (LAP), and the mature $25 \mathrm{kDa}$ TGF- $\beta$, whereas the SLC lacks latent TGF- $\beta$-binding protein and only comprises LAP and mature TGF- $\beta .^{3}$ The association of LAP with the mature TGF- $\beta$ homodimer is noncovalent and essential for latency, as it is only when this interaction is disrupted that the $25 \mathrm{kDa}$ growth factor can bind to its receptors. ${ }^{4}$ Most cells secrete at least one TGF- $\beta$ isoform and express TGF- $\beta$ receptors that have known biological activators. For instance, activators release TGF- $\beta$ either by degrading LAP and/or latent TGF- $\beta$-binding proteins or by modifying the conformation of the latent complex. Integrins $\alpha_{v} \beta_{6}, \alpha_{v} \beta_{8}$, and reactive oxygen species are specific activators for particular TGF- $\beta$ isoforms, because of differences in the sequence of LAP of each isoform. In addition, other activators (e.g., platelet thrombospondin 1 , certain proteases, low $\mathrm{pH}$ conditions, and high temperatures) activate all three isoforms. ${ }^{5-7}$

Pregnancy-specific $\beta$-glycoprotein 1 (PSG1) is synthesized by the human placenta and is secreted into the maternal circulation in an increasing concentration from the time of trophoblast differentiation until term. ${ }^{8}$ PSG1 is the most abundantly expressed of the 11 different PSG genes that reach a median concentration of $168 \mu \mathrm{g} \mathrm{ml}^{-1}$ at week 36 of pregnancy, when a plateau is reached. ${ }^{9}$ PSGs belong to

\footnotetext{
${ }^{1}$ Charité Center 12 Internal Medicine and Dermatology, Reproductive Medicine Research Group, Medicine University Berlin, Berlin, Germany. ${ }^{2}$ Department of Pathology, Uniformed Services University of the Health Sciences, Bethesda, Maryland, USA. ${ }^{3}$ Department of Cell Biology, New York University School of Medicine, New York, New York, USA and ${ }^{4}$ Mucosal Immunity Section, Laboratory of Clinical Investigation, National Institute of Allergy and Infectious Diseases, National Institutes of Health, Bethesda, Maryland, USA. Correspondence: GS Dveksler (gabriela.dveksler@usuhs.edu)

${ }^{5}$ The first two authors contributed equally to this work.
} 
carcinoembryonic antigen (CEA) family but differ from other CEA family members in that they are secreted rather than membrane bound. Human PSGs are highly glycosylated proteins composed of an immunoglobulin variable-like domain followed by constant-like domains. ${ }^{8}$ Genes coding for PSGs have only been described in species with hemochorial placentation in which fetal cells are in direct contact with the maternal circulation, posing a risk of immune rejection by the mother.

There are 17 murine PSG genes, and the few that have been studied so far appear to have a similar function as demonstrated by in vitro studies. ${ }^{10,11}$ The murine PSG genes are interspersed within chromosome 7 with other members of the CEA family, making it technically difficult to evaluate whether PSGs are essential for pregnancy success. ${ }^{12}$ At this time, the importance of these proteins in pregnancy is supported by clinical studies that indicate that concentrations of PSGs below the normal range are associated with adverse pregnancy outcome. ${ }^{13,14}$ During pregnancy, TGF- $\beta$ regulates trophoblast invasion, angiogenesis, and extracellular matrix production. ${ }^{15}$ In addition, TGF- $\beta$ suppresses $\mathrm{CD}^{+}{ }^{+} \mathrm{T}$ - and natural killer cell cytotoxic functions and is essential for differentiation of extrathymic regulatory $\mathrm{T}$ (Treg) cells that are necessary for the development of tolerance of the maternal immune system to paternal antigens expressed by the fetus. ${ }^{16,17}$ Studies of isoformspecific TGF- $\beta$-null mice demonstrated nonredundant roles of the different TGF- $\beta$ isoforms in development. Although the three isoforms have been shown to be expressed in mucosal tissues and signal through a common receptor subunit, their expression varies in different cell types. In addition, the different TGF- $\beta$ isoforms have recently been reported to vary in their ability to induce the pathogenic function of effector $\mathrm{T}$ helper type 17 cells. ${ }^{18,19}$

Treatment of different cells with PSG1 increased the secretion of total TGF- $\beta 1$ in the supernatant as determined by enzyme-linked immunosorbent assay (ELISA). ${ }^{20,21}$ In addition, we observed that PSG1 induced vascular endothelial growth factor A in a trophoblast cell line in a TGF- $\beta$-dependent manner. ${ }^{22}$ This observation as well as other observations described below prompted us to investigate whether PSG1 bound TGF- $\beta$ and whether PSG1 could also play a role in the process of TGF- $\beta$ activation.

\section{RESULTS}

\section{Recombinant and native PSG1 bind TGF- $\beta$}

First, we determined by ELISA that purified recombinant PSG1-Fc generated in CHO-K1 cells was associated with total (latent + active) TGF- $\beta 1$. Next, we explored whether, besides total TGF- $\beta 1$, PSG1-Fc contained the active form of the cytokine and if the presence of latent and active TGF- $\beta 1$ could also be detected in recombinant PSG1 preparations generated in other cell lines. We found that Protein A-purified PSG1-Fc harvested from the supernatant of transfected HeLa and HEK$293 \mathrm{~T}$ cells was also associated with TGF- $\beta 1$. At concentrations of PSG1-Fc $>15 \mu \mathrm{g} \mathrm{ml}^{-1}$, some of the TGF- $\beta 1$ was in the active form, as detection by ELISA did not require prior acidification. Supplementary Table S1 online shows results obtained with individual PSG1-Fc preparations. Active and latent TGF- $\beta 1$ were also detected in recombinant PSG1-HisFLAG secreted from stably transfected CHO-K1 cells after elution from a HisTrap and an anti-FLAG agarose column (Supplementary Table S1 online). Besides mature TGF- $\beta 1$, PSG1 purified from HeLa and HEK-293T cells contained LAP- $\beta 1$ (Figure 1a). We did not test for the presence of LAP in PSG1 made in CHO-K1 cells because of the lack of available reagents to detect hamster LAP. The PSG1/LAP interaction was confirmed using HeLa cells expressing a recombinant PSG1 that contains the transmembrane-anchorage domain of CEACAM1 (HeLa-PSG1). ${ }^{8}$ HeLa-PSG1 cells had significantly higher levels of LAP bound to their membrane when compared with untransfected HeLa cells (Figure 1b). PSG1-Fc secreted

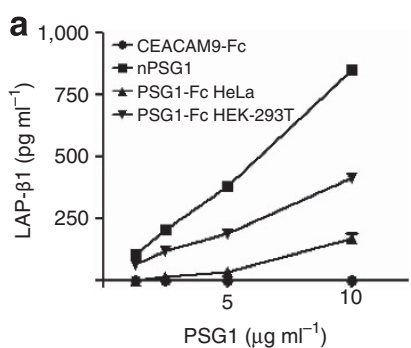

b



C

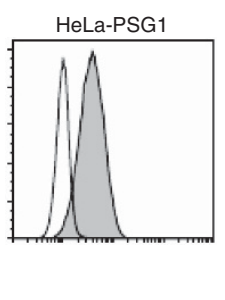

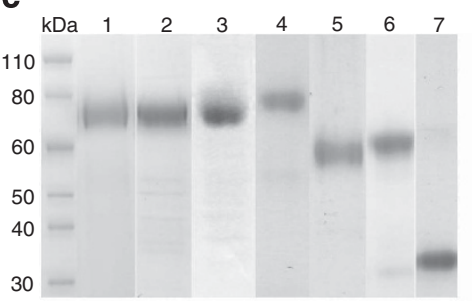

d

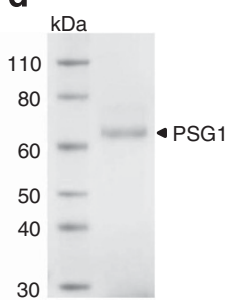

Figure 1 Latency-associated protein- $\beta 1$ (LAP- $\beta 1)$ is present in recombinant and native pregnancy-specific glycoprotein 1 (PSG1)/transforming growth factor- $\beta 1$ (TGF- $\beta$ ) complexes. (a) Different concentrations of recombinant PSG1 or control protein CEACAM9-FC generated in HEK-293T and HeLa cells and PSG1 purified from pooled sera of pregnant women (native PSG1 (nPSG1)) were tested by enzyme-linked immunosorbent assay (ELISA) for the presence of LAP- $\beta 1$ as indicated in the Methods. (b) HeLa-PSG1 and the parental HeLa cells transfected with empty plasmid were incubated with phycoerythrin (PE)-labeled anti-human LAP- $\beta 1$ monoclonal antibody ( $\mathrm{mAb}$; full gray) or PE-labeled isotype control (empty white). (c) PSG1-Fc was generated in CHO-K1 (lane 1), HEK-293T (lane 2), HeLa (lane 3), and mouse embryonic fibroblast (MEF) cells derived from TGF- $\beta 1$-null mice (lane 4). The supernatant of the transfected cells was purified on a protein A column. PSG1-His-FLAG was generated in CHO-K1 cells (lane 5) and was purified with a HisTrap column, followed by an anti-FLAG column. The control proteins Ceacam9-Fc (lane 6) and FLAG-Fc (lane 7) were purified from the supernatant of transfected CHO-K1 cells on a protein A column. After purification, proteins were concentrated, buffered exchange into phosphate-buffered saline (PBS), and run on sodium dodecyl sulfate-polyacrylamide gel electrophoresis (SDS-PAGE). The GelCode Blue-stained gel shown here is a composite of lanes run in different gels. (d) PSG1 was purified from pooled serum of pregnant women by affinity chromatography with anti-PSG1 mAb 4. The eluted material was concentrated, buffered exchange into PBS run on SDS-PAGE, and stained with GelCode Blue. A full color version of this figure is available at the Mucosal Immunology journal online. 
from transfected mouse embryonic fibroblasts (MEFs) derived from TGF- $\beta 1$-null mice and PSG1 generated in insect cells, which we had used for our initial studies in monocytes, had undetectable levels of associated TGF- $\beta 1$. This is expected as these cells do not express this cytokine and were grown in serum-free conditions. ${ }^{20}$ Interestingly, PSG1-Fc generated in the TGF- $\beta 1$-null fibroblasts contained latent TGF- $\beta 2$, which could only be detected at $>30 \mu \mathrm{g} \mathrm{ml}^{-1}$ concentrations of PSG1, with some variations in the concentration of TGF- $\beta 2$ observed between preparations (Supplementary Table S1 online). These results indicate that recombinant PSG1 generated in different cell lines can bind to TGF- $\beta 1$ and TGF- $\beta 2$. CEACAM9, like PSG1, is a member of the CEA family expressed in the placenta and FLAG-Fc is a recombinant protein containing the same tags as the recombinant PSG1 used for most of our studies. CEACAM9-Fc and FLAG-Fc were generated and purified under identical conditions as PSG1-Fc. These proteins were used as controls and were evaluated in parallel at equimolar concentrations as the different preparations of PSG1 in each experiment. We did not detect TGF- $\beta 1,-\beta 2$, or LAP- $\beta 1$ in the control proteins up to the highest concentration tested, which was $100 \mu \mathrm{g} \mathrm{ml}^{-1}$. All recombinant proteins utilized for these studies are shown in Figure 1c.

To determine whether native PSG1 bound LAP- $\beta 1$ and mature TGF- $\beta 1$, we affinity purified PSG1 from sera of pregnant women (Figure 1d). We found that all four native PSG1 preparations, each purified from different batches of pooled sera from pregnant women, carried TGF- $\beta 1$ and LAP- $\beta 1$. As observed with recombinant PSG1 preparations, there was some variation in the concentration of PSG1 at which LAP- $\beta 1$ and mature TGF- $\beta 1$ were detected and in the amounts of these moieties carried by the different preparations. In addition, we tested for the presence of TGF- $\beta 2$ in different preparations of native PSG1 up to a PSG1 concentration of $80 \mu \mathrm{g} \mathrm{ml}^{-1}$. We found that latent TGF- $\beta 2$ was detected in two out of four pregnant sera PSG1 preparations. Supplementary Table S1 online shows the ELISA results obtained for one of the native PSG1 preparations that carried TGF- $\beta 2$.

\section{PSG1 activates latent TGF- $\beta 1$ and TGF- $\beta 2$}

We next examined whether PSG1 is a passive TGF- $\beta$ carrier, like apolipoprotein E3 and surfactant protein A, or if unlike these molecules, PSG1 functions as an activator of the latent form of this cytokine. ${ }^{23,24}$ To address this issue, we added PSG1 generated in the MEF TGF- $\beta 1$-null cells to TGF- $\beta$ reporter cell lines, which are useful for detecting the presence of active TGF- $\beta$ but that themselves only secrete the latent form of this cytokine. Importantly, in these experiments, PSG1 was used at concentrations at which we could not detect any isoform of TGF- $\beta$ associated with the protein. To test whether PSG1 could activate latent TGF- $\beta 1$ secreted from cells, we generated a stable TGF- $\beta$ reporter cell line by transducing HEK-293T cells with lentivirus particles containing the firefly luciferase gene under the control of a minimal cytomegalovirus promoter and tandem repeats of the SMAD transcriptional response element (HEK-SMAD reporter). Specific ELISAs for all three isoforms demonstrated that this cell line expresses only latent TGF- $\beta 1$ with an average of $182 \mathrm{pg} \mathrm{ml}^{-1}$ detected after acid activation of the supernatant harvested after $16 \mathrm{~h}$. Treatment of the HEKSMAD reporter cell line with PSG1-Fc generated in TGF- $\beta 1$ null cells resulted in a dose-dependent increase in luciferase expression compared with the CEACAM9-Fc treated cells (Figure 2a).

The second reporter system tested relies on cells (TMLECs) transfected with a truncated plasminogen activator inhibitor-1 promoter fused to the firefly luciferase reporter gene. ${ }^{25}$ The third bioassay consists of embryonic fibroblasts derived from TGF- $\beta 1$-null mice that were stably transfected with a reported plasmid consisting of TGF- $\beta$-responsive SMAD-binding elements coupled to a secreted alkaline phosphatase (SEAP) reporter gene (MFB-F11). ${ }^{26}$ We found that incubation of the reporter TMLEC and MFB-F11 cell lines with PSG1-Fc resulted in a dose-dependent increase of light units (Figure $\mathbf{2 b}$ ) and of SEAP activity (Figure $2 \mathrm{c}$ ), respectively. The TGF- $\beta 2$ secreted by TMLECs and MFB-F11 cells was all in the latent form, as active TGF- $\beta 2$ could be measured only after acid activation of the conditioned media (average of 280 and $440 \mathrm{pg} \mathrm{ml}^{-1}$ of TGF- $\beta 2$ after $16 \mathrm{~h}$ of incubation, respectively). We could not detect TGF- $\beta 1$ or TGF- $\beta 3$, with or without acid activation, in the conditioned media of these cells. These results strongly suggest that PSG1 converts latent TGF- $\beta 2$ secreted by these cells into its active form.

Importantly, we found that the native PSG1 preparations, which had undetectable levels of all three TGF- $\beta$ isoforms at the concentration utilized for these experiments, had the ability to activate TGF- $\beta 1$ secreted from the HEK-SMAD reporter cells (Figure 2d). Furthermore, native PSG1 activated latent TGF$\beta 2$ secreted from the reporter TMLEC and MFB-F11 cells (Figures 2e,f). As controls, we treated the reporter cells with the control proteins CEACAM9-Fc, Flag-Fc, or with media alone. We did not observe a significant difference in the response of any of these cells to CEACAM9-Fc and Flag-Fc treatments, which were not significantly different to media alone (not shown). As positive control, we treated the cells with different concentrations of mature TGF- $\beta 1$ or TGF- $\beta 2$ (Figures $2 \mathbf{g}-\mathbf{i}$ ). The increase in luciferase and SEAP activity mediated by recombinant and native PSG1 in the three reporter bioassays employed was specific, as it was inhibited by the addition of the ALK5 inhibitor SB 431542 and the pan neutralizing anti-TGF- $\beta$ antibody (Ab) 1D11 (Figures 3a-d).

Because some metalloproteinases and serine proteases activate TGF- $\beta,{ }^{27}$ we tested whether the activation of TGF$\beta 1$ and $-\beta 2$ mediated by PSG1 that was observed in the TMLEC, MFB-F11, and HEK-SMAD reporter assays was blocked by the addition of inhibitors of serine and cysteine proteases (leupeptin), aspartate proteases (pepstatin), amino peptidases (bestatin), metallo endopeptidases (phosphoramidon), matrix metalloproteinases (galardin), and anti-papain. None of these protease inhibitors blocked the PSG1-mediated increase in luciferase activity and SEAP expression, which are the 

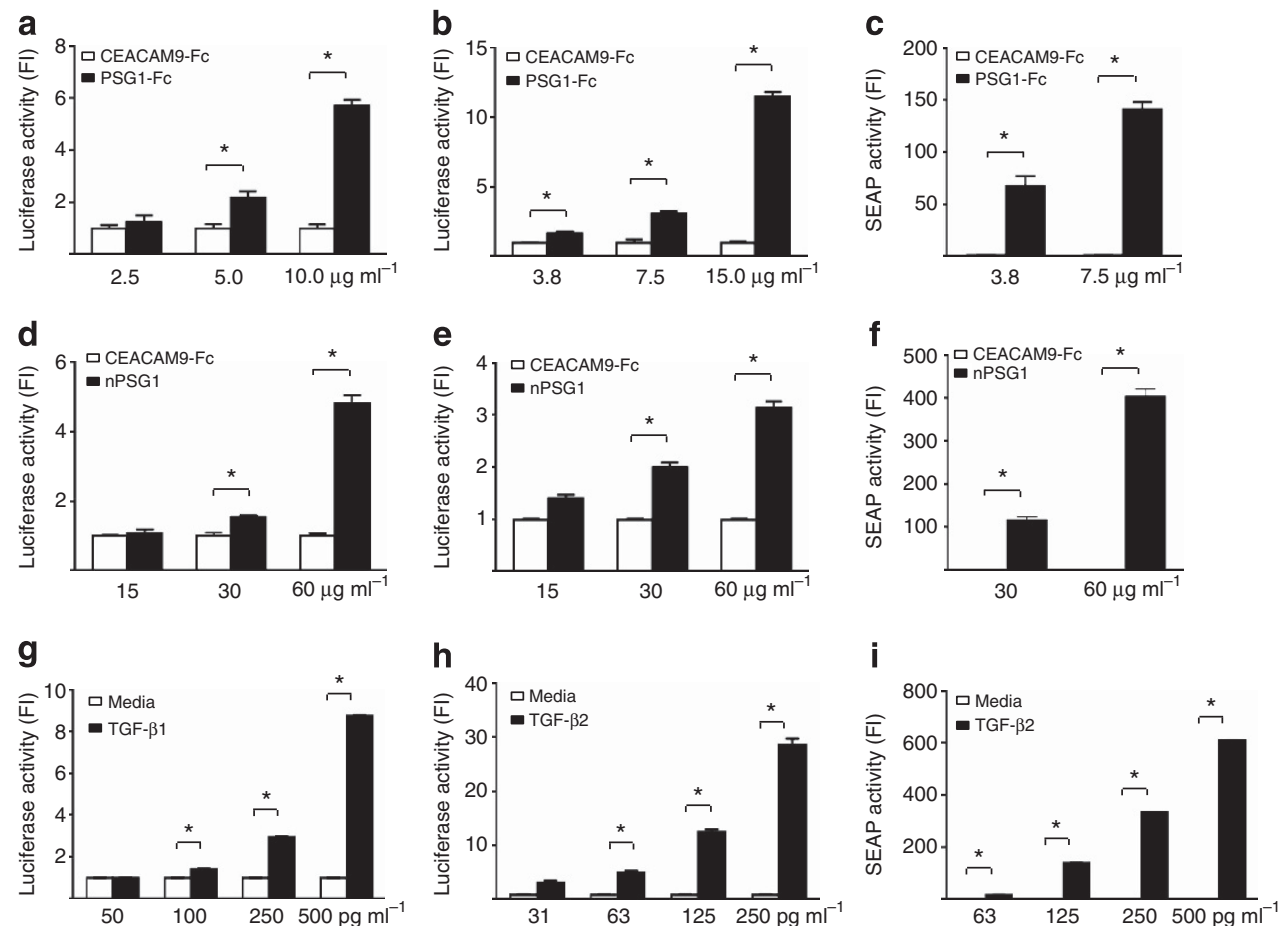

Figure 2 Recombinant and native pregnancy-specific glycoprotein 1 (PSG1) activate transforming growth factor- $\beta$ (TGF- $\beta$ ) secreted in latent form by TGF- $\beta$ reporter cell lines. HEK-SMAD cells were treated with different concentrations of PSG1-Fc made in (a) TGF- $\beta 1$-null mouse embryonic fibroblasts (MEFs), (d) native PSG1 (nPSG1), or (g) mature TGF- $\beta 1$ in Dulbecco's modified Eagle's medium (DMEM)/0.1\% insulin-transferrin-sodium selenite (ITS) and light units were measured in the lysates after $16 \mathrm{~h}$. TMLECs were incubated with different concentrations of PSG1-FC made in (b) TGF- $\beta 1$-null MEFs, (e) native PSG1, or (h) mature TGF- $\beta 2$ in DMEM/0.1\% ITS. Light units were measured in the cell lysates $16 \mathrm{~h}$ after treatment. MFB-F11 cells were incubated with different concentrations of PSG1-Fc made in (c) TGF- $\beta 1$-null MEFs, (f) native PSG1, or (i) mature TGF- $\beta 2$ in DMEM. The reporter (secreted alkaline phosphatase (SEAP)) was measured in the cell supernatant $24 \mathrm{~h}$ after treatment. The three reporter cell lines were also incubated with the control protein CEACAM9-Fc at the same concentration or with DMEM with $0.1 \%$ ITS (HEK-SMAD and TMLECs) or DMEM only (MFB-F11 cells). Results are expressed as Luciferase activity fold induction (FI) or SEAP activity fold induction (FI) after normalization with values obtained upon treatment of the cells with DMEM- $0.1 \%$ ITS or DMEM for MFB-F11 cells. Treatments with PSG1 and CEACAM9-Fc were performed in triplicate wells. Treatments with recombinant mature TGF- $\beta$ s were performed in duplicate wells. All experiments were performed three independent times with similar results. In all figures, significant differences are noted as ${ }^{\star} P<0.05$ as analyzed by Student's $t$-test.

indicators of the presence of the active cytokine (Supplementary Figure S1 online).

\section{PSG1 activates SLC in cell-free conditions}

To determine whether PSG1 activated the SLC of TGF- $\beta 1$ under chemically defined, cell-free conditions, we incubated different concentrations of recombinant and native PSG1 or control protein with SLC of TGF- $\beta 1$ and measured the amount of active TGF- $\beta 1$ as indicated in the Methods section. In addition, as the SLC may contain a small amount of active TGF- $\beta 1$, we incubated SLC in phosphate-buffered saline to determine the concentration of active TGF- $\beta 1$ in each SLC preparation (Figure 4c). We employed two ELISAs to measure active TGF- $\beta 1$, one in which the wells were coated with TGF- $\beta$ RII-Fc and the other in which the wells were coated with an $\mathrm{Ab}$ that binds only to active TGF- $\beta$. In both assays, we observed that PSG1 induced an increase in the concentration of active TGF- $\beta 1$ in a dose dependent manner (Figures $\mathbf{4 a}, \mathbf{b}$ and Supplementary Figure S2 online). Recombinant and native PSG1 without SLC were added to the wells as controls to show that these preparations did not carry any active TGF- $\beta 1$ at the concentrations utilized in these experiments (data not shown).
Recombinant PSG1 generated in insect cells, GST-PSG1d, was also able to activate SLC in the cell-free assay (Supplementary Figure S2 online). Although PSG1 could activate SLC, the amount of active TGF- $\beta 1$ generated was always lower than what was observed upon acid treatment of the SLC, which determines the total available substrate in this assay (Figure 4c and Supplementary Figure S2 online).

\section{Prevention of DSS-induced colitis by administration of PSG1}

The dextran sodium sulfate (DSS) model of colitis has demonstrated several correlations with inflammatory bowel disease. In this model, an alteration of the mucosal barrier results in a macrophage-induced inflammatory response superimposed to T cell-mediated inflammation. ${ }^{28}$ Several studies strongly suggest that activated TGF- $\beta 1$ plays an important role in maintaining intestinal tolerance. ${ }^{29-31}$ Therefore, we hypothesized that administration of PSG1 would ameliorate the intestinal pathology observed in acute colitis induced by DSS administration as TGF- $\beta 1$ and $-\beta 2$ have been suggested to play a nonredundant role in the control of intestinal inflammation. ${ }^{32}$ Mice were given DSS in drinking water and 
were injected intraperitoneally with $100 \mu \mathrm{g}$ of recombinant PSG1-Fc or an equimolar concentration of the control protein Flag-Fc, as described in the Methods section (Figure 5a).
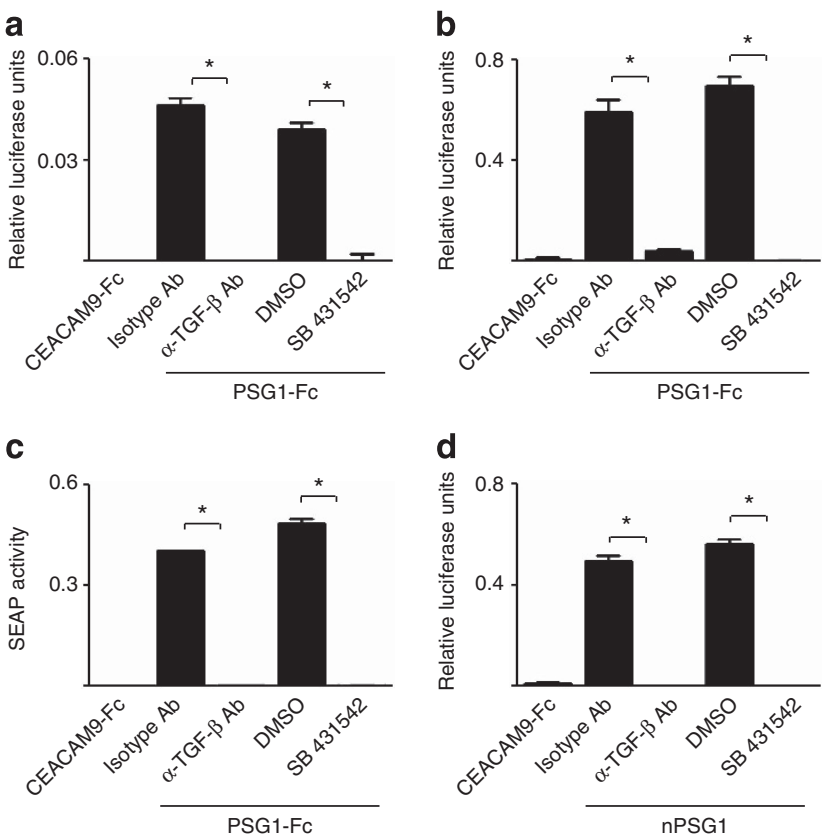

Figure 3 Pregnancy-specific glycoprotein 1 (PSG1)-mediated activation of transforming growth factor- $\beta$ (TGF- $\beta$ ) is inhibited by the pan TGF- $\beta$ neutralizing $1 \mathrm{D} 11$ monoclonal antibody $(\mathrm{mAb})$ and the TGF- $\beta$ receptor kinase inhibitor SB 431542. (a) TMLECs, (b) HEK-SMAD, and (c) MFBF11 cells were treated with $7.5 \mu \mathrm{g} \mathrm{ml}^{-1}$ recombinant PSG1 in the presence of $60 \mu \mathrm{g} \mathrm{ml}^{-1}$ anti-TGF- $\beta$ 1D11 antibody (Ab), isotype control Ab at the same concentration, $5 \mu \mathrm{M} \mathrm{SB} 431542$, or dimethyl sulfoxide (DMSO). (d) HEK-SMAD were treated with $20 \mu \mathrm{g} \mathrm{ml}^{-1}$ native PSG1 (nPSG1) in


and the respective controls. The cells were also incubated with the control protein CEACAM9-Fc at (a-c) $7.5 \mu \mathrm{g} \mathrm{ml}^{-1}$ and (d) $20 \mu \mathrm{g} \mathrm{ml}^{-1}$. Results are expressed as luciferase activity or secreted alkaline phosphatase (SEAP) activity after subtraction of the values obtained upon treatment of the cells with Dulbecco's modified Eagle's medium (DMEM)/ $0.1 \%$ insulin-transferrin-sodium selenite or DMEM for MFB-F11 cells. All treatments were performed in triplicate in three independent experiments. In all figures, significant differences are noted as ${ }^{\star} P<0.05$ as analyzed by Student's $t$-test.
As shown in Figure 5b, animals receiving PSG1 were protected from weight loss and colon shortening, the standard clinical features observed in mice receiving DSS. $^{28}$ In addition, histologic analysis revealed that the colons obtained from PSG1-treated mice had a marked reduction in thickening of the colonic wall, as well as transmural leukocyte infiltration and lost significantly less goblet cells than protein control-treated mice (Figure 5c). Furthermore, there was no evidence of bloody stools in mice receiving PSG1 in contrast to the protein controltreated mice, in which diarrhea and bloody stools were evident at day 6 .

\section{PSG1 effect on cytokine production in mice undergoing DSS colitis}

Next, we determined the effect of intraperitoneal administration of recombinant PSG1 on cytokine production in mice subjected to induction of DSS colitis. For these studies, after the mice were killed, mesenteric lymph node (MLN) cells were obtained from PSG1-Fc or control protein- treated mice. After culture with anti-CD3/anti-CD28 or interferon- $\gamma($ IFN- $\gamma$ ) and Staphylococcus aureus Cowans (SAC) (described in Methods), different cytokines were measured in the culture supernatant. As shown in Figure 5d, MLN cells obtained from mice given control protein produced increased amounts of interleukin-6 (IL-6), tumor necrosis factor- $\alpha$ (TNF- $\alpha$ ), and IFN- $\gamma$ upon stimulation with anti-CD3/anti-CD28. On the other hand, secretion of these cytokines was not increased upon stimulation, when MLN cells were obtained from PSG1treated mice. Similarly, increased secretion of IL- 6 and TNF- $\alpha$ was only observed in MLN cells obtained from control protein but not from PSG1-treated mice upon stimulation with IFN- $\gamma$ and SAC (Figure 5e). Finally, we observed that low amounts of IL-10 could be detected in stimulated MLN cells obtained from both PSG1 and control protein-treated mice (Figure 5d,e). Analysis of cytokine gene expression in the colon showed that mice receiving PSG1 expressed lower levels of IFN- $\gamma$, TNF- $\alpha$, and IL-17 mRNA than control protein-treated mice (Figure 5f). In addition, we observed an increase in IL-10
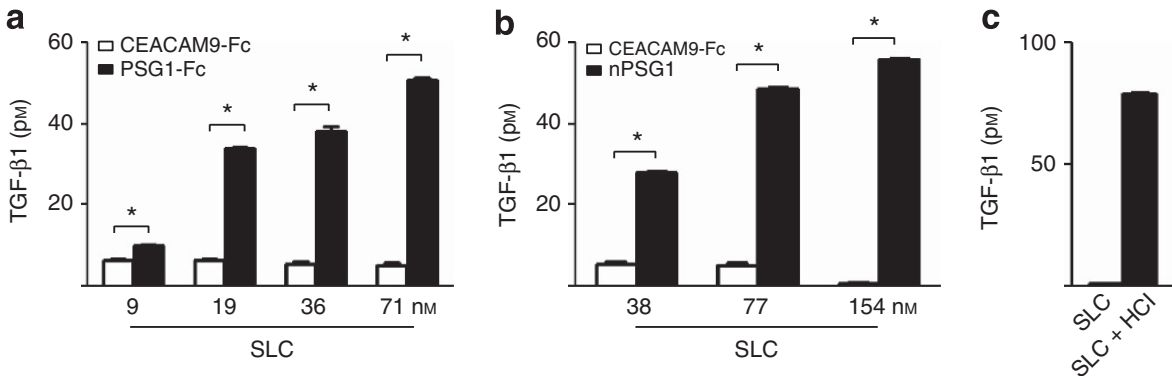

Figure 4 Recombinant and native pregnancy-specific glycoprotein 1 (PSG1) activate the small latent complex (SLC) of transforming growth factor- $\beta 1$ (TGF- $\beta 1$ ) in a cell- free system. PSG1-Fc generated in mouse embryonic fibroblasts (MEFs) derived from (a) TGF- $\beta 1$-null mice, (b) native PSG1 (nPSG1), or the control protein CEACAM9-Fc were incubated in triplicate at increasing concentrations with phosphate-buffered saline (PBS) or with SLC $(0.5 \mathrm{~nm})$ for $1 \mathrm{~h}$ at $37^{\circ} \mathrm{C}$, after which they were added to wells coated with TGF- $\beta$ RII-Fc. The presence of active TGF- $\beta 1$ was quantified after incubation with biotin-labeled anti-mature TGF- $\beta 1$ antibody (Ab) and streptavidin-horseradish peroxidase (HRP). (c) The amount of TGF- $\beta 1$ already in the active form in the recombinant SLC and the concentration of active TGF- $\beta 1$ that was obtained upon acid activation of the SLC were determined in parallel. All treatments were performed in triplicate in three independent experiments. In all figures, significant differences are noted as ${ }^{*} P<0.05$ as analyzed by Student's $t$-test. 


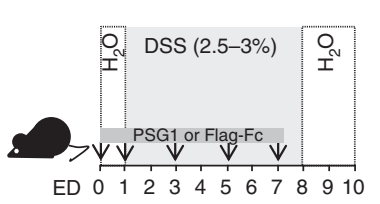

b



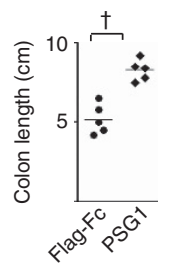

C Flag-Fc



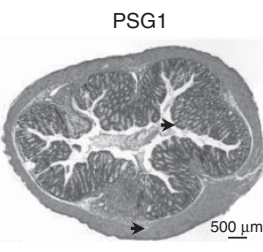

d
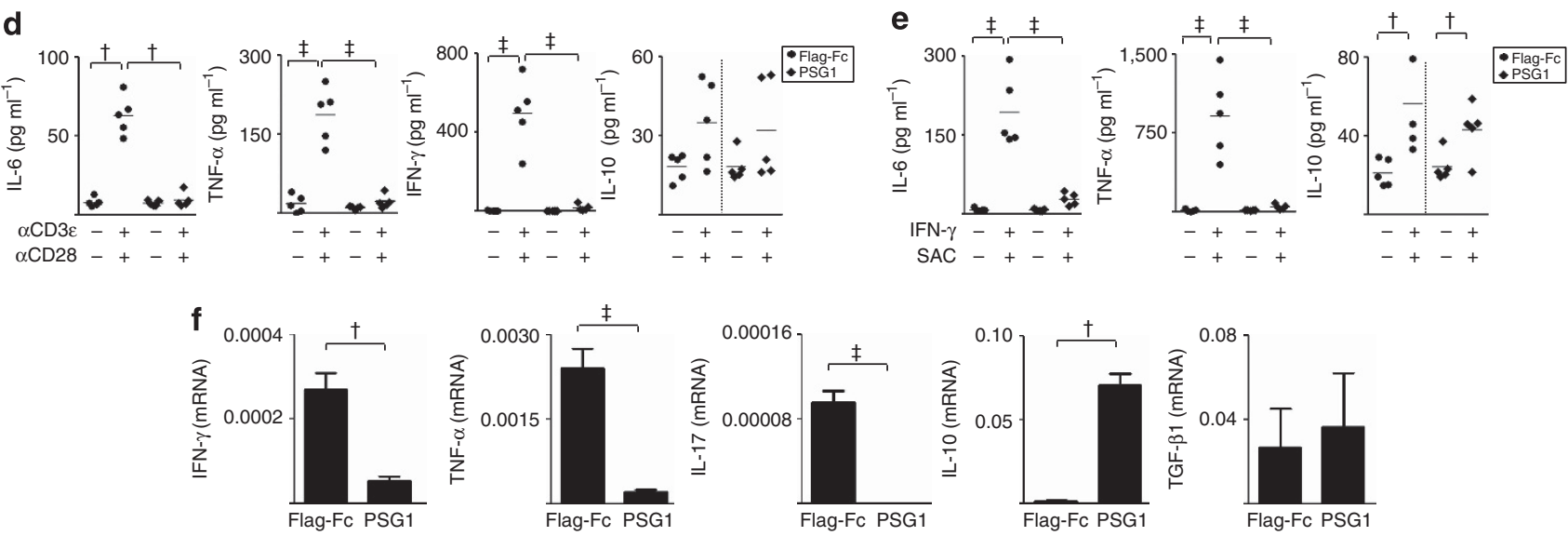

Figure 5 Pregnancy-specific glycoprotein 1 (PSG1) prevents dextran sodium sulfate (DSS)-induced colitis in mice. (a) Acute colitis was induced by administration of 2.5-3\% DSS to the drinking water starting from day 1 to day 7 of the experiment. In addition, mice were injected intraperitoneally either with Flag-Fc (control protein, $\left.30 \mu \mathrm{g} \mathrm{day}^{-1}\right)$ or PSG1 $\left(100 \mu \mathrm{g}_{\text {day }}{ }^{-1}\right)$ on days $0,1,3,5$, and 7 of the experimental day (ED) as described in the Methods. (b) Weight loss (\%) in control (Flag-Fc) and PSG1-treated mice ( $n=5 /$ group) was monitored every day. Colon length was recorded on ED10. (c) Hematoxylin and eosin (H\&E)-stained colon sections on ED10 (original magnification $\times 50$; scale bar $=500 \mu \mathrm{m}$ ). Short arrows, epithelium (top arrow, right panel) and smooth muscle (bottom arrow, right panel); large arrows, cellular infiltrates (left panel). (d) Interleukin-6 (IL-6), tumor necrosis factor- $\alpha$ (TNF- $\alpha$ ), interferon- $\gamma$ (IFN- $\gamma$ ), and interleukin-10 (IL-10) production by lymphocytes isolated from mesenteric lymph nodes (MLNs) and stimulated with CD3 $\varepsilon$ and CD28 for $48 \mathrm{~h}$ as described in the Methods. (e) IL-6, TNF- $\alpha$, and IL-10 production by lymphocytes isolated from MLNs and stimulated with IFN- $\gamma$ and Pansorbin (Staphylococcus aureus Cowans (SAC)) for $48 \mathrm{~h}$ as described in the Methods. In (d) and (e), cytokine concentrations were determined in culture supernatants by cytometric beads array (CBA). (f) IFN- $\gamma$, TFN- $\alpha$, IL-17, IL-10, and transforming growth factor- $\beta 1$ (TGF- $\beta 1$ ) expression in colon tissues on ED10 as analyzed by quantitative reverse transcriptase polymerase chain reaction. In all figures, significant differences are noted as ${ }^{\dagger} P<0.01$ and ${ }^{\ddagger} P<0.001$ as analyzed by one-way analysis of variance (ANOVA) followed by Bonferroni's test. Data shown are mean values \pm s.d. derived from five mice per group each analyzed in duplicate. A full color version of this figure is available at the Mucosal Immunology journal online.

mRNA expression in the colon upon PSG1 treatment and no significant changes in the expression of TGF- $\beta 1$ mRNA (Figure 5f). Taken together, these results show that PSG1 can significantly reduce the generation of two T helper type 1 cytokines implicated in the development of mucosal inflammation, TNF- $\alpha$ and IFN- $\gamma$, that are negatively regulated by TGF- $\beta$ and of the pro-inflammatory cytokine IL- 17 .

To evaluate whether the in vivo protective effect of PSG1 in the DSS colitis model could be correlated with the activation of TGF- $\beta$ by PSG1 observed in vitro, we administered anti-TGF- $\beta$ $\mathrm{Ab}$ or a control Ab together with PSG1 or the control protein at days 0 and 3 (Figure 6a). We observed that coadministration of neutralizing anti-TGF- $\beta$ Ab precluded the protective effect of administration of PSG1 as shown in Figures $\mathbf{6 b}, \mathbf{c}$. In accordance with these results, we observed that administration of anti-TGF- $\beta$ Ab to the PSG1-treated mice revealed increased histological signs of inflammation with clear signs of immune cell infiltration and epithelial erosion when compared with mice receiving PSG1 alone or PSG1 with control Ab (Figure 6d). On the other hand, cotreatment with anti-TGF- $\beta$ $\mathrm{Ab}$ did not have a significant effect on the protein controltreated mice, which again experienced significant weight loss, colon shortening, and pathology (Figure $\mathbf{6 b}-\mathbf{d}$ ). In response to anti-CD3/anti-CD28 stimulation, MLN cells obtained from PSG1-treated mice coinjected with anti-TGF- $\beta$ Ab secreted significantly more IL-6, TNF- $\alpha$, and IFN- $\gamma$ than MLN cells obtained from PSG1-treated mice that received control $\mathrm{Ab}$ (Figure 6e). On the other hand, no significant change in IL-17 was observed when comparing the stimulated cells obtained from PSG1-treated mice upon administration of the neutralizing anti-TGF- $\beta \mathrm{Ab}$ and the control $\mathrm{Ab}$ (Figure 6f). An increase in IL-17 secretion was observed in the protein control-treated mice that received the neutralizing anti-TGF- $\beta$ $\mathrm{Ab}$ (Figure 6f). When MLN cells were stimulated with IFN- $\gamma$ and SAC, there was a significant increase of IL- 6 and TNF- $\alpha$ in the PSG1-treated mice receiving the anti-TGF- $\beta$ Ab compared with the mice that received PSG1 and control Ab (Figure 6g).

\section{PSG1 increases the frequency of lamina propria CD4 ${ }^{+}$ $T$ cells expressing LAP and FoxP3 in a TGF- $\beta$-dependent manner}

TGF- $\beta$ converts Foxp $3^{-}$CD $4{ }^{+}$T cells into FoxP3 ${ }^{+}$regulatory cells. ${ }^{2}$ In addition, stimulation of mouse $\mathrm{CD} 4{ }^{+} \mathrm{CD} 25^{-} \mathrm{T}$ cells with recombinant TGF- $\beta$ increases the cell surface expression 
a

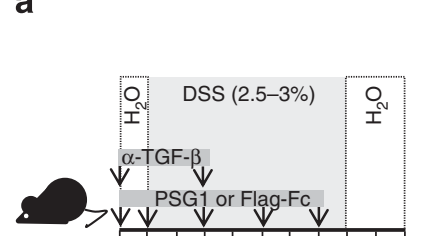

ED $\begin{array}{llllllllllll}0 & 1 & 2 & 3 & 4 & 5 & 6 & 7 & 8 & 9 & 10\end{array}$
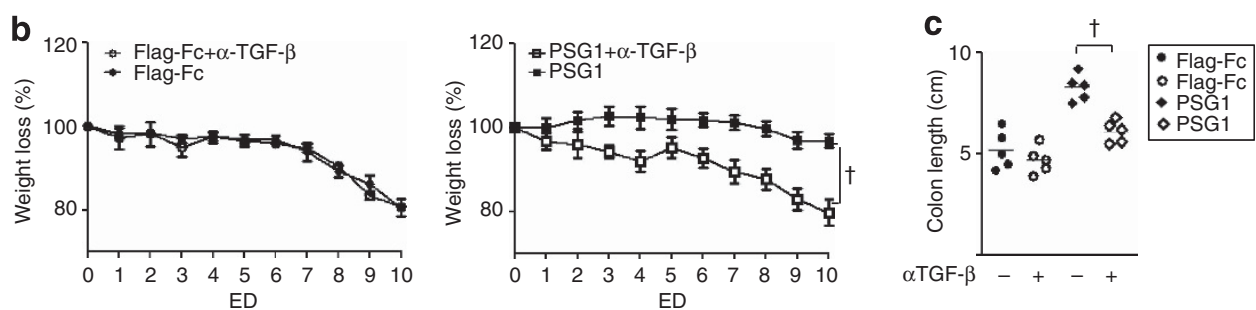
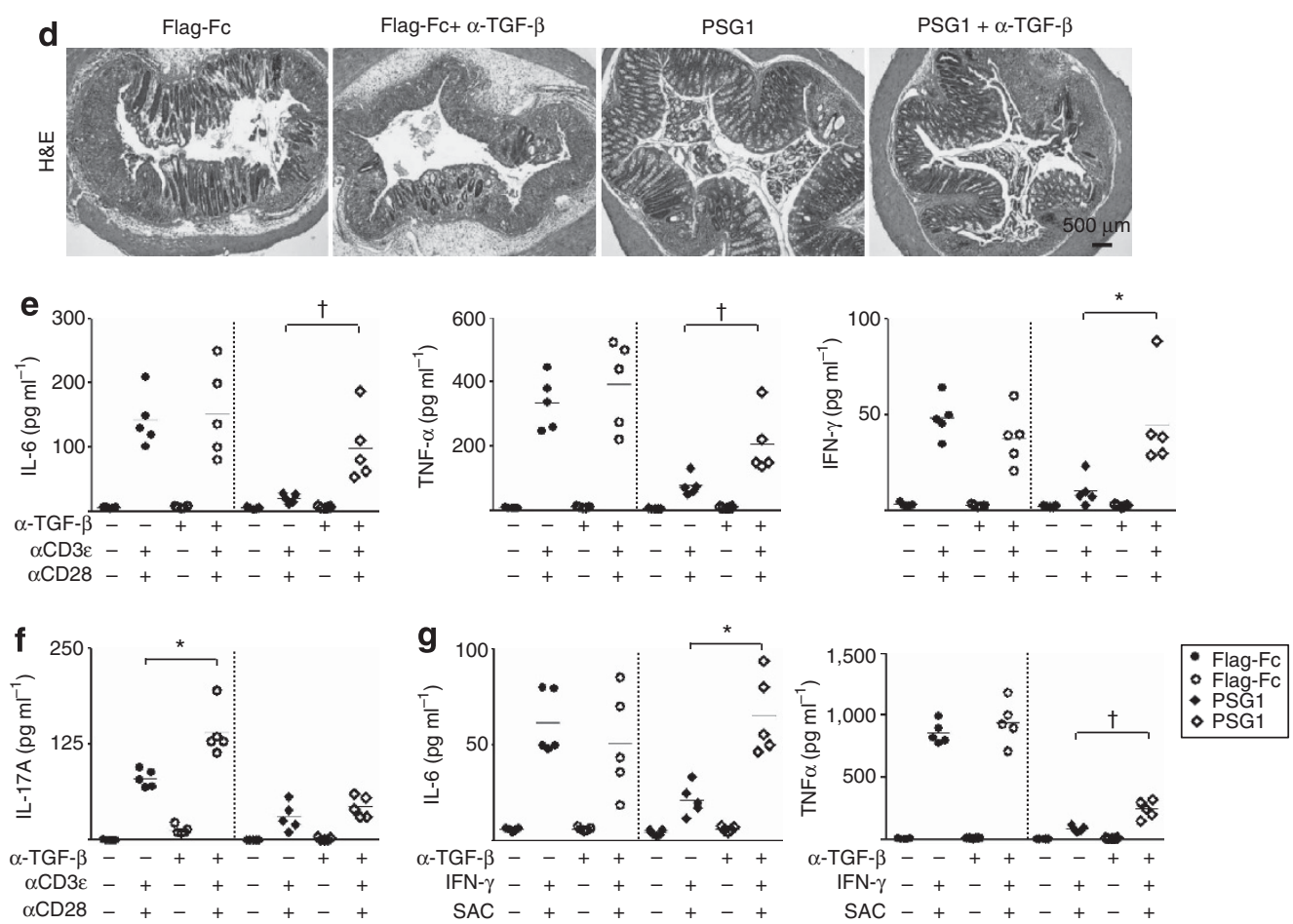

Figure 6 Administration of anti-transforming growth factor- $\beta$ (TGF- $\beta$ ) abrogates the protective effect of pregnancy-specific glycoprotein 1 (PSG1) in dextran sodium sulfate (DSS)-induced colitis. (a) Experimental design. DSS-treated mice were injected intraperitoneally either with Flag-Fc (control protein, $30 \mu \mathrm{g} \mathrm{day}^{-1}$ ) or PSG1 $\left(100 \mu \mathrm{g} \mathrm{day}^{-1}\right.$ ) on experimental days (EDs) $0,1,3,5$, and 7 . In addition, the mice received anti-TGF- $\beta$ $\left(1 \mathrm{mg} \mathrm{day}^{-1}\right)$ or isotype control antibody on EDO and ED3 as described in the Methods. (b) Weight was monitored every day. Data are presented as weight loss (\%). (c) Colon length recorded on ED10. (d) Hematoxylin and eosin (H\&E)-stained colon sections on ED10. (e) Interleukin-6 (IL-6), tumor necrosis factor- $\alpha$ (TNF- $\alpha$ ), interferon- $\gamma$ (IFN- $\gamma$ ), and (f) interleukin-17 (IL-17) production by lymphocytes isolated from mesenteric lymph nodes (MLNs) and stimulated with CD3 $\varepsilon$ and CD28 for $48 \mathrm{~h}$ as described in the Methods. (g) IL-6 and TNF- $\alpha$ production by lymphocytes isolated from MLNs and stimulated with IFN- $\gamma$ and Pansorbin (Staphylococcus aureus Cowans (SAC)) for $48 \mathrm{~h}$ as described in the Methods. In (d) and (e), cytokine concentrations were determined in culture supernatants by cytometric beads array (CBA). In all panels, significant differences are noted as ${ }^{\star} P<0.05$ and ${ }^{\dagger} P<0.01$ as analyzed by one-way analysis of variance (ANOVA) followed by Bonferroni's test. Data shown are mean \pm s.d. derived from five mice per group, each analyzed in duplicate. A full color version of this figure is available at the Mucosal Immunology journal online.

of LAP, which reflects the protective regulatory function of these cells in intestinal inflammation. ${ }^{33}$ Therefore, we hypothesized that administration of PSG1 might increase the number of $\mathrm{FoxP}^{+}$and $\mathrm{LAP}^{+}$cells in the colonic lamina propria (LP), a normal site of accumulation of Treg cells specific for commensal bacteria. LP mononuclear cells were isolated and stained for surface expression of CD4 and LAP and for intracellular expression of FoxP3 (forkhead box P3) as indicated in Methods. We observed a significant increase in the percentage and absolute number of cells expressing both LAP and FoxP3 in mice that received PSG1 when compared with protein control-treated mice (Figures $7 \mathbf{a}, \mathbf{b}$ ). This increase was markedly inhibited in mice receiving PSG1 in conjunction with the neutralizing anti-TGF- $\beta$ Ab, strongly suggesting that the effects of PSG1 resulting in the increase of Tregs were at least partially mediated by active TGF- $\beta$ (Figures $7 \mathbf{a}-\mathbf{c}$ ). In addition, administration of anti-TGF- $\beta$ Ab had an effect in lowering the number of $\mathrm{FoxP}^{+} / \mathrm{LAP}^{+}$cells in the protein control-treated mice (Figures $7 \mathbf{a}-\mathbf{c}$ ).

\section{DISCUSSION}

Recombinant PSG1 induces the secretion of TGF- $\beta 1$ by human monocytes, bone marrow-derived dendritic cells, and the RAW 264.7 macrophage cell line. ${ }^{20,21}$ Here we report that PSG1 has associated LAP- $\beta 1$ and mature TGF- $\beta 1$. This interaction was detected by ELISA and was observed in different forms of recombinant PSG1, regardless of the strategy employed to purify the protein and the nature of the tag present in the 

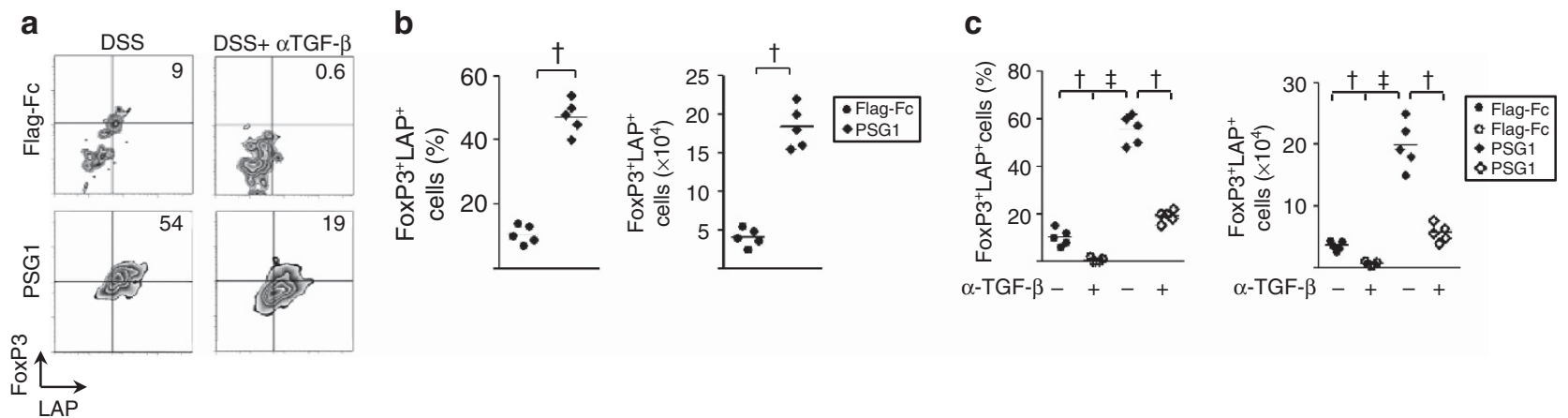

Figure 7 Administration of pregnancy-specific glycoprotein 1 (PSG1) increases the frequency of $\mathrm{CD}^{+}{ }^{+} \mathrm{FoxP}^{+}{ }^{+} \mathrm{LAP}^{+}$lymphocytes in the lamina propria (LP). (a) Representative plots of FoxP3 and latency-associated protein (LAP)-stained CD4 ${ }^{+}$lymphocytes isolated from LP were analyzed by flow cytometry (FACS). (b) Percentages and absolute numbers of FoxP3 ${ }^{+} \mathrm{LAP}^{+}$LP lymphocytes isolated from Flag-Fc or PSG1 dextran sodium sulfate (DSS)-treated mice are depicted. (c) Percentages and absolute numbers of FoxP3 ${ }^{+} \mathrm{LAP}^{+} \mathrm{LP}_{\text {lymphocytes isolated from }}$ Flag-Fc or PSG1 DSS- $\alpha$-TGF- $\beta$-treated mice are shown. All treatments were performed in triplicate in two independent experiments using five mice per group. In all figures, significant differences are noted as ${ }^{\dagger} P<0.01$ and ${ }^{\ddagger} P<0.001$ as analyzed by one-way analysis of variance (ANOVA) followed by Bonferroni's test. Data shown are mean \pm s.d. derived from five mice per group, each analyzed in duplicate.

recombinant PSG1. In addition, we demonstrated the interaction between PSG1 and LAP- $\beta 1$ by expressing a membranebound form of PSG1 in HeLa cells. Therefore, our results indicate that LAP and TGF- $\beta$, which are non-covalently bound to each other, associate with PSG1 rather than copurify with it. As expected, recombinant PSG1 generated in insect cells, which do not produce TGF- $\beta$, had no detectable associated TGF- $\beta$, whereas PSG1 generated in MEFs obtained from TGF- $\beta 1$-null cells only had associated TGF- $\beta 2$. Importantly, PSG1 purified from pooled serum of pregnant women also contained LAP- $\beta 1$ and mature TGF- $\beta 1$ and some preparations contained TGF- $\beta 2$. We could not assay these samples for the presence of LAP- $\beta 2$ as there are no available reagents for its detection. At this time, we cannot explain why all preparations of PSG1 did not contain both TGF- $\beta$ isoforms, but this may be related to the fact that the serum was pooled irrespective of gestational age or that the concentration of TGF- $\beta 2$ may vary between individuals.

Using three different TGF- $\beta$ reporter cell lines, we observed that addition of recombinant and PSG1 purified from pregnant serum resulted in an increase of active TGF- $\beta$ that could signal in these cells. Addition of different proteases inhibitors did not preclude the increase in active TGF- $\beta$ mediated by PSG1 observed in the TGF- $\beta$ reporter assays, suggesting that the mechanism of action of PSG1 is protease independent and may be similar to that of thrombospondin $1 .^{7}$ To understand the mechanism by which PSG1 addition resulted in an increase of TGF- $\beta$ signaling in the reporter cell lines, we incubated PSG1 with latent SLC in a cell-free system. As shown in Figure 4 and Supplementary Figure S2 online, PSG1 converted some of the latent SLC into its active form. Further studies are required to determine whether, like thrombospondin 1, PSG1 induces a conformational change in the TGF- $\beta$ latent complex of the TGF- $\beta 1$ and -2 isoforms and also activates TGF- $\beta 3$. In addition, we observed that recombinant and native PSG1 activated the SLC of TGF- $\beta 1$ in a cell-free system in a dosedependent manner. This result indicates that neither PSG1 nor the latent complex have to be anchored to the cell membrane, which is a requirement for some TGF- $\beta$ activators. ${ }^{34}$

TGF- $\beta 1$ and TGF- $\beta 2$ are considered potent anti-inflammatory cytokines and have been shown to mediate suppression of the Thelper type 1 response in models of induced colitis and to regulate intestinal macrophage cytokine production. We explored the therapeutic potential of PSG1 administration in a murine model of acute DSS-induced colitis and evaluated the role of TGF- $\beta$ in this system. We observed that administration of PSG1 was highly effective in preventing induction of colitis. The mechanism by which PSG1 exerts this protective effect is in great part mediated by one or more TGF- $\beta$ isoforms, as the PSG1 protective effect was not observed in the presence of the pan neutralizing anti-TGF- $\beta$ Ab. The inhibition of TNF- $\alpha$ and IFN- $\gamma$ by PSG1 in the colitis model is likely relevant in the context of pregnancy, as these cytokines have been reported to have potent abortogenic properties. ${ }^{35}$ In addition to TGF- $\beta$, IL-10 has been previously linked to the prevention of colitis. The relationship of TGF- $\beta$ and IL-10 is complex; TGF- $\beta$ induces IL-10 secretion and IL-10 secreted by a subset of macrophages in the LP maintains Foxp3 expression and suppressive function in mice with colitis. ${ }^{36,37}$ Although PSG1 treatment increased the mRNA expression of IL-10 in the colon, we did not detect a further increase in IL-10 protein upon stimulation of MLN cells isolated from PSG1-treated mice over the increase observed upon stimulation of MLN cells isolated from the protein control-treated mice. This may be explained by a difference in the production of IL- 10 by myeloid cells in the colon and in the MLNs, and a difference in the level of TGF- $\beta$ between these tissues. Previously, we reported an increase of TGF- $\beta 1$ secretion by PSG1 in monocytes but we could not detect an increase of TGF- $\beta 1$ mRNA. This result is in agreement with the lack of increase of TGF- $\beta 1$ mRNA in the colon on PSG1 treatment. The release of intracellular existing TGF- $\beta 1$ rather than new synthesis has been previously shown to contribute to the increase in TGF- $\beta 1$ in several experimental conditions. ${ }^{38}$ 
PSG1 binds to heparan sulfate (HS) proteoglycans, including the HS chains in all four syndecans. This interaction is required for the ability of PSG1 to induce endothelial tube formation but it is not known whether cell surface HS can modulate the ability of PSG1 to induce the secretion of cytokines. ${ }^{39}$ Interestingly, mature TGF- $\beta 1$ trapped on the T-cell surface by syndecan- 4 has been proposed to potentiate inhibition of T-cell activation. ${ }^{40}$ The domain(s) of PSG1 involved in PSG1 binding to HS and to LAP and/or mature TGF- $\beta$ have yet to be identified. It is therefore possible that although bound to HS moieties in syndecan- 4 expressed on activated T cells, PSG1 could activate TGF- $\beta$ and that some of the active TGF- $\beta$ remains bound to HS on syndecan. This would increase the availability of mature TGF- $\beta$ that could be presented to another cell as well as its halflife. A similar mechanism could be envisioned in the surface of the placenta. Active TGF- $\beta$ has been described to be associated with the syncytiotrophoblast plasma membrane and microvilli. The syncytiotrophoblast exhibits apical expression of syndecan- 1 that also binds active TGF- $\beta{ }^{41}$ Therefore, TGF- $\beta$ may bind to TGF- $\beta$ receptors on the trophoblast or it may stay associated with syndecan-1 and PSG1 and be presented to maternal cells. In this context, decidual natural killer cells are susceptible to TGF- $\beta$ regulation and have a distinct phenotype from those from the peripheral blood. ${ }^{42}$ It is therefore possible that PSG1 increases the availability of active TGF- $\beta$ and in this way influences natural killer phenotype during pregnancy.

Although pregnancy has a clear beneficial effect in diseases such as rheumatoid arthritis, multiple sclerosis, and systemic sclerosis, there is no consensus regarding the beneficial effects of pregnancy in diseases affecting mucosal surfaces such as inflammatory bowel disease. The rate of disease flare during pregnancy is similar to nonpregnant flare rates, although there have been some suggestions that Crohn's disease symptoms might improve during gestation. ${ }^{43,44}$ Although PSG1 may have some therapeutic potential for inflammatory bowel diseases, the increase in regulatory $\mathrm{T}$ cells could potentially increase the susceptibility to infections. Therefore, further studies are required before the use of PSG1 as a therapeutic agent is considered. Recently, Martinez et al. ${ }^{21}$ showed that PSG1 affects the maturation of bone marrow-derived dendritic cells and that intraperitoneal infection of mice with a vaccinia virus expressing PSG1 promoted the expansion of antigen-specific $\mathrm{CD}^{+}{ }^{+} \mathrm{CD} 25^{+}$Foxp3 $^{+}$Treg cells in response to Listeria monocytogenes infection. In our experiments, using a different model, we observed an increase in the frequency of $\mathrm{CD} 4{ }^{+}$cells expressing FoxP3 and cell surface LAP. Further studies are required to understand the contribution of PSGs in the expansion of Tregs, which occurs physiologically during pregnancy. ${ }^{17}$ In addition, the possibility that PSG1 may increase the suppressive activity of Tregs and/or the conversion of naive cells to Tregs by activating the membrane-bound form of latent TGF- $\beta 1$ expressed on activated Tregs remains to be explored.

Phylogenetic analysis of the CEA family strongly suggests that one of the primordial genes in this family is CEACAM1 (CEA-related cell adhesion molecule) that has been shown to have immune regulatory functions, the nature of which is dependent on the splice variant expressed. ${ }^{45}$ Our observations and those of others indicate that some members of the CEA family regulate the innate and adaptive immune response by using different mechanisms, which may be related to their sites of expression and may have evolved in parallel to the type of placentation. This newly described activity of PSG1 reinforces previous clinical observations on the importance of PSGs in the establishment and maintenance of a successful pregnancy in humans and provides a mechanism for their proposed role as immune modulators.

\section{METHODS}

Protein production and purification. PSG1-Fc, PSG1-His-FLAG, and the control proteins were harvested from the supernatant of transiently or stably transfected cells and purified as previously reported. ${ }^{22}$ GSTPSG1 (isoform d) was generated as previously described. ${ }^{20}$ Detailed description is available in Supplementary Information online.

Induction of colitis and PSG treatment. DSS $(36-50 \mathrm{kDa}, \mathrm{MP}$ Biomedical, Solon, $\mathrm{OH}$ ) was used to supplement the drinking water of 6-8-week old C57BL/6 mice at 2.5-3\% (w/v) solution for 7 days. Fresh solution was replaced after 3 days and given ad libitum. On day 7 , mice were returned to normal drinking water and monitored for an additional 3 days. Body weight and diarrhea were recorded daily. At the time of killing, mice were evaluated for colon length and a portion of the colon then removed, fixed in $10 \%$ buffered formalin, and embedded in paraffin. Colon samples were cut in $4-\mu \mathrm{m}$ sections, stained with hematoxylin and eosin, and examined by light microscopy. PSG1-Fc (100 $\mu \mathrm{g}$ in $200 \mu \mathrm{l}$ of phosphate-buffered saline) or an equimolar concentration of the control protein (Flag-Fc) were injected intraperitoneally the day before the mice were given DSS (experimental day 0), on the first day of DSS administration (experimental day 1) and every other day until DSS-containing water was replaced with normal drinking water (experimental day 7). When indicated, $1 \mathrm{mg}$ of anti-TGF- $\beta$ or isotype control antibodies were administered together with the first and third protein injections. Procedures that involved mice were approved by state authority and the Medicine University of Berlin committee on Animal Use in Research and Education.

Isolation of LP and MLN cells. LP mononuclear cells were isolated from LP by gradient centrifugation with the Lympholyte-M density separation medium. For a detailed description, please see Supplementary Information online.

Cytokine determination by cytometric bead arrays. Cytokines were analyzed in cell culture supernatants using cytometric bead arrays from BD Biosciences (San Jose, CA). Detailed description is available in Supplementary Information online.

RNA isolation and quantitative PCR analysis. Total RNA was isolated and converted into complementary DNA with Superscript II (Invitrogen, Grand Island, NY) and random primers. Real-time PCR was performed with the Power SYBR Green PCR master mix (Invitrogen) and the specific primers. Detailed description is available in Supplementary Information online.

Luciferase and SEAP assays. Reporter bioassays were performed as previously described. ${ }^{25,26}$ Detailed descriptions of these protocols are available in Supplementary Information online. Results are expressed as Luciferase activity fold induction or SEAP activity fold induction after normalization with values obtained on treatment of the cells with Dulbecco's modified Eagle's medium/ $0.1 \%$ insulin-transferrin-sodium selenite or Dulbecco's modified Eagle's medium for MFB-F11 cells. 
Statistics. Treatments presented in Figures 1-4 were performed in triplicate and values are given as mean \pm standard error of the mean (s.e.m.) of the triplicate wells for each treatment. Statistical analysis was performed using Student's $t$-test and $P<0.05$ was considered statistically significant. Differences between treatments with the same protein at different concentrations were calculated by oneway analysis of variance. Statistical analysis for in vivo experiments was calculated by one-way analysis of variance and Bonferroni's multiple comparison tests. Statistically significant differences between groups are indicated as ${ }^{\star} P<0.05,{ }^{\dagger} P<0.01$, and ${ }^{\ddagger} P<0.001$.

SUPPLEMENTARY MATERIAL is linked to the online version of the paper at http://www.nature.com/mi

\section{ACKNOWLEDGEMENTS}

Research reported in this publication was supported by National Institute of Allergy and Infectious Diseases of the National Institutes of Health (NIH) under award number R21Al101979 and by the National Institutes of Child Health and Human Development of the NIH under award number R01HD035832 to G.S.D.; and S.M.B. was supported by a Deutsche Forschungsgemeinschaft (DFG) grant BL1115/1-1. We thank Dr WyssCoray (Stanford University) for the MFB-F11 reporter cells and MEF derived from TGF- $\beta 1$-null mice, $\mathrm{Dr}$ L. Wakefield $(\mathrm{NIH})$ and $\mathrm{Dr}$ C. Stuelten $(\mathrm{NIH})$ for their invaluable advice, Dr W. Zimmermann (University of Munich) for providing us with the HeLa-PSG1 cells and the plasmid encoding CEACAM9-Fc, Dr F. Lisboa for helpful discussions, and Dr S. Jonjic for the anti-PSG1 \#4 Ab (University of Rijeka).

\section{DISCLOSURE}

The authors declared no conflict of interest.

\section{DISCLAIMER}

The opinions expressed here are those of the authors and should not be construed as official or reflecting the views of the Uniformed Services University of the Health Sciences or the Department of Defense.

(c) 2014 Society for Mucosal Immunology

\section{REFERENCES}

1. Massague, J., Blain, S.W. \& Lo, R.S. TGFbeta signaling in growth control, cancer, and heritable disorders. Cell 103, 295-309 (2000).

2. Li, M.O. \& Flavell, R.A. TGF-beta: a master of all T cell trades. Cell 134, 392-404 (2008).

3. Miyazono, K., Hellman, U., Wernstedt, C. \& Heldin, C.H. Latent high molecular weight complex of transforming growth factor beta 1. Purification from human platelets and structural characterization. J. Biol. Chem. 263, 6407-6415 (1988).

4. Walton, K.L. et al. Two distinct regions of latency-associated peptide coordinate stability of the latent transforming growth factor-beta1 complex. J. Biol. Chem. 285, 17029-17037 (2010).

5. Jobling, M.F. et al. Isoform-specific activation of latent transforming growth factor beta (LTGF-beta) by reactive oxygen species. Radiat. Res. 166, 839-848 (2006).

6. Munger, J.S. et al. The integrin alpha v beta 6 binds and activates latent TGF beta 1: a mechanism for regulating pulmonary inflammation and fibrosis. Cell 96, 319-328 (1999).

7. Ribeiro, S.M., Poczatek, M., Schultz-Cherry, S., Villain, M. \& MurphyUllich, J.E. The activation sequence of thrombospondin-1 interacts with the latency-associated peptide to regulate activation of latent transforming growth factor-beta. J. Biol. Chem. 274, 13586-13593 (1999).

8. Zhou, G.Q. et al. Highly specific monoclonal antibody demonstrates that pregnancy-specific glycoprotein (PSG) is limited to syncytiotrophoblast in human early and term placenta. Placenta 18, 491-501 (1997).

9. Pluta, M., Hardt, W., Schmidt-Gollwitzer, K. \& Schmidt-Gollwitzer, M. Radioimmunoassay of serum SP 1 and HPL in normal and abnormal pregnancies. Arch. Gynecol. 227, 327-336 (1979).
10. Blois, S.M. et al. Early expression of pregnancy-specific glycoprotein 22 (PSG22) by trophoblast cells modulates angiogenesis in mice. Biol. Reprod. 86, 191 (2012).

11. Wu, J.A., Johnson, B.L., Chen, Y., Ha, C.T. \& Dveksler, G.S. Murine pregnancy-specific glycoprotein 23 induces the proangiogenic factors transforming-growth factor beta 1 and vascular endothelial growth factor a in cell types involved in vascular remodeling in pregnancy. Biol. Reprod. 79, 1054-1061 (2008).

12. McLellan, A.S. et al. Structure and evolution of the mouse pregnancyspecific glycoprotein (Psg) gene locus. BMC Genomics 6, 4 (2005).

13. Pihl, K., Larsen, T., Laursen, I., Krebs, L. \& Christiansen, M. First trimester maternal serum pregnancy-specific beta-1-glycoprotein (SP1) as a marker of adverse pregnancy outcome. Prenat. Diagn. 29, 1256-1261 (2009).

14. Grudzinskas, J.G., Gordon, Y.B., Menabawey, M., Lee, J.N., Wadsworth, J. \& Chard, T. Identification of high-risk pregnancy by the routine measurement of pregnancy-specific beta 1-glycoprotein. Am. J. Obstet. Gynecol. 147, 10-12 (1983).

15. Jones, R.L., Stoikos, C., Findlay, J.K. \& Salamonsen, L.A. TGF-beta superfamily expression and actions in the endometrium and placenta. Reproduction 132, 217-232 (2006).

16. Andersson, J. et al. CD4 + FoxP3 + regulatory T cells confer infectious tolerance in a TGF-beta-dependent manner. J. Exp. Med. 205, 1975-1981 (2008).

17. Aluvihare, V.R., Kallikourdis, M. \& Betz, A.G. Regulatory T cells mediate maternal tolerance to the fetus. Nat. Immunol. 5, 266-271 (2004).

18. Letterio, J.J. \& Roberts, A.B. Transforming growth factor-beta1-deficient mice: identification of isoform-specific activities in vivo. J. Leukoc. Biol. 59, 769-774 (1996).

19. Lee, Y. et al. Induction and molecular signature of pathogenic $\mathrm{TH} 17$ cells. Nat. Immunol. 13, 991-999 (2012).

20. Snyder, S.K. et al. Pregnancy-specific glycoproteins function as immunomodulators by inducing secretion of IL-10, IL- 6 and TGF-beta1 by human monocytes. Am. J. Reprod. Immunol. 45, 205-216 (2001).

21. Martinez, F.F., Knubel, C.P., Sanchez, M.C., Cervi, L. \& Motran, C.C. Pregnancy-specific glycoprotein 1a activates dendritic cells to provide signals for Th17-, Th2-, and Treg-cell polarization. Eur. J. Immunol. 42, 1573-1584 (2012).

22. Ha, C.T. et al. Human pregnancy specific beta-1-glycoprotein 1 (PSG1) has a potential role in placental vascular morphogenesis. Biol. Reprod. 83, 27-35 (2010).

23. Kunzmann, S. et al. TGF-beta1 in SP-A preparations influence immune suppressive properties of SP-A on human CD4+T lymphocytes. Am. J. Physiol. Lung Cell Mol. Physiol. 291, L747-L756 (2006).

24. Tesseur, I. et al. Bioactive TGF-beta can associate with lipoproteins and is enriched in those containing apolipoprotein E3. J. Neurochem. 110, 1254-1262 (2009).

25. Abe, M., Harpel, J.G., Metz, C.N., Nunes, I., Loskutoff, D.J. \& Rifkin, D.B. An assay for transforming growth factor-beta using cells transfected with a plasminogen activator inhibitor-1 promoter-luciferase construct. Anal. Biochem. 216, 276-284 (1994).

26. Tesseur, I., Zou, K., Berber, E., Zhang, H. \& Wyss-Coray, T. Highly sensitive and specific bioassay for measuring bioactive TGF-beta. BMC Cell Biol. 7 , 15 (2006).

27. Munger, J.S., Harpel, J.G., Gleizes, P.E., Mazzieri, R., Nunes, I. \& Rifkin, D.B. Latent transforming growth factor-beta: structural features and mechanisms of activation. Kidney Int. 51, 1376-1382 (1997).

28. Strober, W., Fuss, I.J. \& Blumberg, R.S. The immunology of mucosal models of inflammation. Annu. Rev. Immunol. 20, 495-549 (2002).

29. Boirivant, M. et al. Inhibition of Smad7 with a specific antisense oligonucleotide facilitates TGF-beta1-mediated suppression of colitis. Gastroenterology 131, 1786-1798 (2006).

30. Travis, M.A. et al. Loss of integrin alpha(v)beta8 on dendritic cells causes autoimmunity and colitis in mice. Nature 449, 361-365 (2007).

31. Lacy-Hulbert, A. et al. Ulcerative colitis and autoimmunity induced by loss of myeloid alphav integrins. Proc. Natl. Acad. Sci. USA 104, 15823-15828 (2007).

32. Konkel, J.E. \& Chen, W. Balancing acts: the role of TGF-beta in the mucosal immune system. Trends Mol. Med. 17, 668-676 (2011).

33. Oida, T. \& Weiner, H.L. TGF-beta induces surface LAP expression on murine CD4 T cells independent of Foxp3 induction. PLoS One 5, e15523 (2010). 


\section{ARTICLES}

34. Annes, J.P., Chen, Y., Munger, J.S. \& Rifkin, D.B. Integrin alphaVbeta6mediated activation of latent TGF-beta requires the latent TGF-beta binding protein-1. J. Cell. Biol. 165, 723-734 (2004).

35. Clark, D.A., Arck, P.C. \& Chaouat, G. Why did your mother reject you? Immunogenetic determinants of the response to environmental selective pressure expressed at the uterine level. Am. J. Reprod. Immunol. 41, 5-22 (1999).

36. Fuss, I.J., Boirivant, M., Lacy, B. \& Strober, W. The interrelated roles of TGFbeta and IL-10 in the regulation of experimental colitis. J. Immunol. 168, 900-908 (2002).

37. Murai, M. et al. Interleukin 10 acts on regulatory $T$ cells to maintain expression of the transcription factor Foxp3 and suppressive function in mice with colitis. Nat. Immunol. 10, 1178-1184 (2009).

38. Chen, W., Frank, M.E., Jin, W. \& Wahl, S.M. TGF-beta released by apoptotic $T$ cells contributes to an immunosuppressive milieu. Immunity 14, 715-725 (2001).

39. Lisboa, F.A. et al. Pregnancy-specific glycoprotein 1 induces endothelial tubulogenesis through interaction with cell surface proteoglycans. J. Biol. Chem. 286, 7577-7586 (2010).
40. Chung, J.S., Shiue, H., Duvic, M., Pandya, A., Cruz, P.D. Jr. \& Ariizumi, K. Sezary syndrome cells overexpress syndecan-4 bearing distinct heparan sulfate moieties that suppress T-cell activation by binding DC-HIL and trapping TGF-beta on the cell surface. Blood 117, 3382-3390 (2011).

41. Selick, C.E., Horowitz, G.M., Gratch, M., Scott, R.T. Jr., Navot, D. \& Hofmann, G.E. Immunohistochemical localization of transforming growth factor-beta in human implantation sites. J. Clin. Endocrinol. Metab. 78, 592-596 (1994).

42. Keskin, D.B. et al. TGFbeta promotes conversion of CD16 + peripheral blood NK cells into CD16- NK cells with similarities to decidual NK cells. Proc. Natl. Acad. Sci. USA 104, 3378-3383 (2007).

43. Confavreux, C., Hutchinson, M., Hours, M.M., Cortinovis-Tourniaire, P. \& Moreau, T. Rate of pregnancy-related relapse in multiple sclerosis. Pregnancy in Multiple Sclerosis Group. N. Engl. J. Med. 339, 285-291 (1998).

44. Beaulieu, D.B. \& Kane, S. Inflammatory bowel disease in pregnancy. World J. Gastroenterol. 17, 22696-22701 (2011).

45. Chen, L. et al. The short isoform of the CEACAM1 receptor in intestinal T cells regulates mucosal immunity and homeostasis via Th cell induction. Immunity 37, 930-946 (2012). 